\title{
THE COMPARISON OF HEALTH CARE SYSTEMS THROUGH REGIONAL ANALYSIS: THE CASE OF HOSPITAL ADMISSIONS IN BELGIUM AND THE NETHERLANDS
}

\author{
Peter P. Groenewegen and Jouke Van der Zee \\ Netherlands Institute of Primary Health Care, P.O. Box 1568, 3500 BN Utrecht, The Netherlands
}

\begin{abstract}
One of the problems in the international comparison of health care systems is the small number of units of analysis. Usually only a small number of systems is compared which makes cross-sectional statistical analysis impossible. The two obvious solutions to this problem-neither of which is generally feasible-are either to enlarge the number of systems being compared or to use time series on a small number of health care systems. Quite another solution is to study regional variations within and between a small number of systems. The number of regions has to be sufficiently large to make statistical analysis possible. This is the solution chosen in this article. The phenomenon which is central to our analysis is the number of hospital admissions per 1000 of the population. To explain variations in the hospital admission rate, it is hypothesized that there are a number of variables that have the same kind of influence on hospital admission rates in all western industrialized countries (such as the supply of hospital beds and the health status of the population). On the other hand there are determinants of regional variation in the number of admissions which either exert an influence dependent on the nature of the system, or are unique to a particular health care system. Concerning the first group of hypotheses (the general model), our analysis based on data for 1974 showed that the only variables to have a clear and equal influence on the regional variation in hospital admission rates in the Netherlands as well as in Belgium are the number of hospital beds per 1000 inhabitants and standardized mortality (an operationalization of the concept of health status). The influence of system-specific variables (the second group of hypotheses) has been analysed, taking the difference between the actual number of admissions and the number of admissions expected on the basis of the number of beds and mortality as the dependent variable. In the Netherlands, none of the variables appears to have a clear influence on the level of this ratio, whereas in Belgium there is a greater number of admissions than expected in regions with a higher birthrate and a higher number of both general practitioners and specialists in the common disciplines (internal medicine, pediatrics, gynaecology) in relation to the total number of specialists.
\end{abstract}

Key words -international comparisons, regional variations, hospital admissions

\section{INTRODUCTION}

The comparative analysis of health care systems is a relatively underdeveloped field in health services research and more so in geography of health and health care. The analysis is in most cases descriptive and narrative. Quantitative analysis is much less common in this field than in other fields of health services research.

One of the reasons for this rather underdeveloped state is that it is very difficult to collect comparable data on a sufficient number of health care systems to allow statistical analysis. In this paper we propose a seldom applied solution to this problem. It is the comparative analysis through the analysis of regional variations within two or more health care systems [1].

Our first objective in this paper is to set out this method of comparing health care systems. Secondly, we will describe the results of an application of this method to the analysis of variations in hospital admission rates between regions in two health care systems, that of Belgium and of the Netherlands. The question here is, how can regional variations in hospital admission rates in Belgium and the Netherlands be explained? The rest of the paper is devoted to this question. We will start with a theoretical analysis in two steps. First, we specify those influences on variation in hospital admission rates which are the same for both countries and secondly, through an analysis of differences in the incentive structure in both health care systems, we will try to specify deviation from these general influences. Next we will describe the data and methods used. We will then proceed to the results of our analysis.

We will conclude our paper with a discussion of the results in terms of the specific question of the explanation of regional variation in hospital admission rates in the countries studied and, more generally, in terms of the usefulness of our approach to the comparative analysis of health care systems.

\section{THE COMPARATIVE ANALYSIS OF HEALTH CARE SYSTEMS}

Two approaches may be distinguished in the comparison of health care systems. Using the first, authors, usually from different countries, write a paper on the health care systems of their respective countries according to the guidelines set by editors. The perspective is holistic in the sense that it aims to give an impression of the health care system as a whole. Analysis is usually confined to an introduction or a concluding chapter by the editors. Examples of these kinds of studies are legion, e.g. the recent volume edited by Raffel [2]. 
The analytical element is more prominent in the second approach, because the perspective is confined to certain aspects of the systems compared and (this may be equally important), in most cases, the study is conducted by one or two researchers who collect and analyse the data-also for countries other than their own. Examples are Blanpain [3] and Glaser [4] who restrict themselves mainly to health insurance, or Roemer and Roemer [5] on manpower policy. In most cases the accent is on policy questions such as: what can we learn from the experience of other countries?

The objective of these studies is not to explain the workings of health care systems, but to describe health care systems or demonstrate the usefulness of solutions in other systems. These are legitimate and useful objectives of health services research. However, it is difficult to use the results of these studies to answer questions that aim at an explanation of phenomena, such as: do the costs of the health care sector in different countries vary with the amount of state regulation in the field of health care and if so, why? To answer questions like this it is necessary to have data that are suitable to statistical analysis.

The question then is how a statistical, comparative analysis of health care systems can be realized. There are a number of solutions. The most obvious is to gather data from a large number of systems, large enough to allow for statistical analysis. In practice, it is very difficult to gather data on as many as 50 different health care systems [6]. The same applies, mutatis mutandis, for the second solution, which would be to use time series data on a smaller number of health care systems. However, it is already difficult to find time series on health care for one country, let alone for a number of countries.

The third solution, the one we propose here, is to extend the number of units by using regions within different health care systems as the units of analysis. This approach restricts the kinds of phenomena that can be studied to those that show regional variation, such as the use of medical procedures, the utilization of medical services and the spatial distribution of manpower. Differences between countries in the percentage of the GNP used for health care can by definition not be studied at a regional level.

The phenomenon chosen in the application worked out in this paper, is that of the regional variation in hospital admission rates in two health care systems. Hospital admissions play a key role in the dynamics of health care systems and-equally importantlythere are comparable data available on a regional scale.

The theoretical approach explaining these regional variations-worked out in the next section-consists of two steps. The first is the identification of variables that influence regional variations in hospital admission rates in the same manner in both countries. The results of the statistical analysis of regional variation in the number of hospital admissions in different industrialized countries point to a number of variables that influence hospital admissions irrespective of the differences between health care systems. Examples of these variables are the degree of urbanization of a region and the number of hospital beds
[7]. These relations are summarized in what we call the general model.

The second step is the identification of variables that reflect the differences between health care systems, either because they have a different influence on regional variation in the number of hospital admissions in the countries studied, or because they only exist in one of the two countries. Examples of such variables are the number of publicly insured patients per region in health care systems with a mixed insurance system or the regional variation in the number of referrals to hospital based specialists in health care systems with a clear division between first and second line providers. We call these relations the specific model.

A GENERAL MODEL FOR THE EXPLANATION OF REGIONAL VARIATIONS IN THE NUMBER OF HOSPITAL ADMISSIONS AND THE INFLUENCE OF DIFFERENCES IN THE HEALTH CARE SYSTEMS

The use of health care facilities is influenced by the demand for and supply of these facilities. In the general model, we restrict ourselves to those variables which are hypothesized to have the same influence in Belgium and the Netherlands on the hospital admission rate. In the specific model we discuss the influence of a number of characteristic differences between the two health care systems. These concern the direct access to medical specialists, the remuneration of health care providers, aspects of the hospital system, the insurance system and the fact that in the Netherlands a large proportion of deliveries still take place at home.

It should be stressed that the hypotheses we formulate here are on a high level of aggregation, while the reasoning on which they are based starts from the incentive structure of the health care system and the decisions of providers and consumers of health care.

Explanations of regional differences in the number of hospital admissions must take these decisions into account. It is, however, difficult to start at the level of individual decisions and to predict the step by step consequences on the number of hospital admissions. In most cases several consequences are equally plausible, because there is no information on the behavioural characteristics of the different decision makers and because of the fact that decisions are linked in a conceptually difficult feedback system. This does not release us from the obligation to state our predictions as clearly as possible and to describe the line of reasoning which connects individual behaviour and outcomes. However, as long as we cannot test hypotheses at a lower level of aggregation and as long as we have no clear picture of the dependencies and feedback mechanism, it is not possible to make precise predictions.

\section{The general model}

As far as the demand side is concerned, we distinguish two groups of parameters, those indicating the health status of the population and those indicating cultural or attitudinal differences in the propensity to seek professional help. 
The health status of the population of a region has a direct influence on the hospital admission rate. Measurement of the health status of a population is a frequently discussed, but seldom adequately solved problem in health services research. Even if it were possible to construct a satisfactory index of the health status of the population of a single country (e.g. based on self-reported morbidity, self-reported health or expert opinion), it would be very difficult to compare data on different countries. Mortality is an exception; whatever the health care system and the administrative procedures are, people do die and deaths are reasonably well recorded by the age, sex and place of residence of the deceased. The probability of a prior hospital admission varies with the cause of death. The cause of death is also recorded in the Netherlands and in Belgium; however the validity of these recordings is frequently questioned, even in analyses of a single country. Consequently, the most direct (and available) indicator for regional differences in health status is mortality. Apart from this, a more indirect indicator of the health status of a population is age distribution. Older people are in general less healthy than younger people, resulting in a higher utilization of health services. Because of the fact that crude mortality rates will reflect age differences between regions and between the Netherlands and Belgium, we have used standardized mortality ratios. The standardized mortality ratio and the age distribution may therefore be used as (theoretically) independent indicators of the health status of the population.

The second group of parameters on the demand side concerns cultural or attitudinal differences in the propensity to seek medical care. Indicators for these differences are the degree of urbanization and the socio-economic composition of a region. Although the literature reviewed by Rothberg [7] is not unequivocal on these points, we hypothesize that the number of hospital admissions relates positively to urbanization and negatively to the socio-economic composition of a region. The socio-economic composition is of course not only a parameter indicating cultural differences in the propensity to seek medical care, at an individual level it also forms the dividing line in most public health insurance schemes. Accordingly, socio-economic composition could be included in the general as well as in the specific model. We chose the first, because more specific indicators are available for the insurance system.
The relations on the demand side of the general model can be summarized in a few propositions about regional differences in the number of hospital admissions per 1000 of the population:

- the higher the number of elderly people in a region, the higher the number of hospital admissions;

- the higher the standardized mortality ratio in a region, the higher the number of hospital admissions;

- the more urbanized a region is, the higher the number of hospital admissions;

- the higher the socio-economic status of a region is, the lower the number of hospital admissions.

The number of hospital admissions, is of course influenced by the availability of hospital facilities and of alternative treatment facilities such as nursing homes for the elderly and ambulatory care clinics. The availability of hospital facilities can be indicated by the number of hospital beds and the number of hospital based physicians, whereas the availability of alternatives to hospital care could be indicated by the number of beds in nursing homes and the number of ambulatory care physicians. In our general model we only use the number of hospital beds per 1000 of the population (and the average length of stay, because of the logical relation between the two and the hospital admission rate). The number of hospital based and ambulatory care physicians is part of the specific model, because of the difference in access to medical specialists between the two countries. Regional data on the number of beds in nursing homes are unfortunately not available [8]. The only proposition about the supply side of the general model is therefore:

- given the average length of stay in hospitals, the higher the number of hospital beds in a region, the higher the number of hospital admissions.

The influence of differences between the health care systems: the specific model

There are a number of important differences between the health care systems of Belgium and the Netherlands. These differences are in the field of access to specialist care, remuneration of family physicians, the hospital system (although the differences are rather small in this respect) and the health insurance system. These differences are summarized in Fig. 1. They are explained in the text with regard

\begin{tabular}{|c|c|c|}
\hline & THE NETHERLANDS & BELGIUM \\
\hline $\begin{array}{l}\text { - access to specialist care } \\
\text { - remuneration of family } \\
\text { physicians }\end{array}$ & $\begin{array}{l}\text { only after refercal } \\
\text { capitation fee ( } 708 \text { of pop.), } \\
\text { fee for service ( } 308 \text { of pop.) }\end{array}$ & $\begin{array}{l}\text { direct access } \\
\text { fee for service }\end{array}$ \\
\hline $\begin{array}{l}\text { - remuneration of specia- } \\
\text { lists }\end{array}$ & fee for service & Eee for service \\
\hline $\begin{array}{l}\text { - range of practice situ- } \\
\text { ations of specialists }\end{array}$ & small, mainly hospital based & wide \\
\hline - hospitals & financed per bed day & idem \\
\hline - ownership of hospitals & private and public & $\begin{array}{l}\text { idem + health in- } \\
\text { surance fund } \\
\text { owned hospitals }\end{array}$ \\
\hline - insurance system & based on German system & $\begin{array}{l}\text { based on French } \\
\text { system }\end{array}$ \\
\hline
\end{tabular}

Fig. 1. Some important differences between the health care systems of Belgium and the Netherlands. 
to the consequences of these differences for regional variations in the number of hospital admissions.

In the Netherlands people can only consult a medical specialist on referral from a family physician. One could argue that this is a barrier to specialist care and as family physicians cannot treat their patients in the hospital, also a barrier to hospitalization. The hypothesis would be that a higher density of family physicians is positively correlated with a lower admission rate. In Belgium medical specialists are directly accessible, although direct access is common practice only to 'primary care specialists' (pediatricians, gynaecologists and internists). There is no barrier as in the Netherlands between family medicine and specialist care. One could therefore hypothesize that a higher density of primary care specialists is positively correlated with admission rates.

However, the situation is more complicated because of a difference in the remuneration of family physicians. In the Netherlands, the physician's decision to treat the patient himself or to refer has no consequences for his income. Family physicians in the Netherlands receive a yearly capitation fee for their publicly insured patients irrespective of the number of services they render to these patients. Although referring or treating a patient does not have consequences for the incomc of family physicians, it has consequences for their free time. When free time is defined as total available time minus the time spent in patient care, it will be clear that referring patients results in more free time without loss of income. More family physicians do not therefore necessarily imply fewer hospital admissions. It means lower mean physician incomes, and the only way to improve returns is to gain more free time through referrals [9].

In Belgium the fee-for-service remuneration of family physicians and medical specialists, combined with direct access of patients to specialist care, induces physicians to treat their patients themselves. In the Netherlands specialists are, as in Belgium remunerated on fee for service basis. Consequently the income of specialists depends on the number of services they can charge to the health insurance funds (as far as the publicly insured patients are concerned). Private patients pay the specialist directly and obtain reimbursement from their private insurance company. The fee surgical specialists can charge for a service is the same whether the service is rendered in an out-patient clinic or in the hospital. The rules for the fees of other specialists favour short hospital admission [10].

In the Netherlands nearly all medical specialists are hospital based and ambulatory care clinics are connected to the hospitals. In Belgium the variety of practice situations is greater. There medical specialists have the opportunity of working in a hospital, working in an ambulatory care clinic either connected to a hospital or freestanding, or working in a private surgery. Belgian as well as Dutch specialists have to contribute to the operating costs of the hospitals when they treat patients in the hospital or in connected ambulatory care clinics. The difference is that Dutch specialists don't have the opportunity to optimize the proportion of their work in the hospital. We therefore hypothesize a greater incentive for medical specialists in Belgium to treat patients in private surgeries or clinics. The consequences for regional variation in hospital admission rates are that we expect a lower admission rate in regions with a higher number of family physicians and primary care specialists (relative to the population or to the number of other specialists). For the Netherlands, we expect a higher admission rate in regions with a higher density of specialists as such.

The hospital has its own interest in the choices medical specialists make. All in all the shift from in-patient treatment to out-patient treatment is a financial disadvantage to the hospital, but this situation is the same in both countries. The ownership of hospitals differs however. In Belgium the Christian and Socialist health insurance funds own (or manage) a number of hospitals (around 50 in 1976). They stimulate the use of these hospitals by their members through reductions in charges. One method is not to charge co-payment for in-patient care by the medical specialist. The hospitals' strategy will be to reduce costs by lowering the number of hospital admissions. But at the local or regional level the strategy is to keep the member patients out of other (i.e. those not owned by the health insurance funds) hospitals by making the stay in a hospital owned by a health insurance fund more attractive.

The insurance systems of both countries have some important differences. The Dutch system of health insurance is reminiscent of the German system, although it has been adapted to the Dutch situation and has been expanded over time. The Belgian system resembles the French system of health insurance. The main characteristics of the Dutch system are: compulsory public insurance for all employees with incomes below a certain level; voluntary public insurance for independents below a certain income level [11]; private insurance for all above a certain income level; and for the publicly insured ( $70 \%$ of the population) benefits in kind without (until very recently) out of pocket contributions. Utilization rates are higher for the publicly insured population-largely determined by differences in health status [12]. We therefore expect higher hospital admission rates in regions with a greater proportion of the population publicly insured.

The main features of the Belgian health insurance system are: nearly complete coverage by two public insurance schemes-the general scheme for all wageearners and their dependents and pensioners, covering nearly all medical costs; and a special scheme for non-wage-earners, covering only substantial medical costs and with the possibility of reinsuring the minor risks. The level of co-payment depends on the insurance category: widows, orphans, handicapped and pensioners until recently received full reimbursement as long as their income did not exceed a certain level. Because of this complete reimbursement (and their generally lower health status) we expect higher hospital admission rates in regions with a higher percentage of 'non-actives'. We expect that the percentage of the population insured under the special scheme, covering only substantial costs, will correlate negatively with the hospital admission rate.

One remaining point of difference involves home deliveries. In the Netherlands nearly half of the 
General model Specific Model

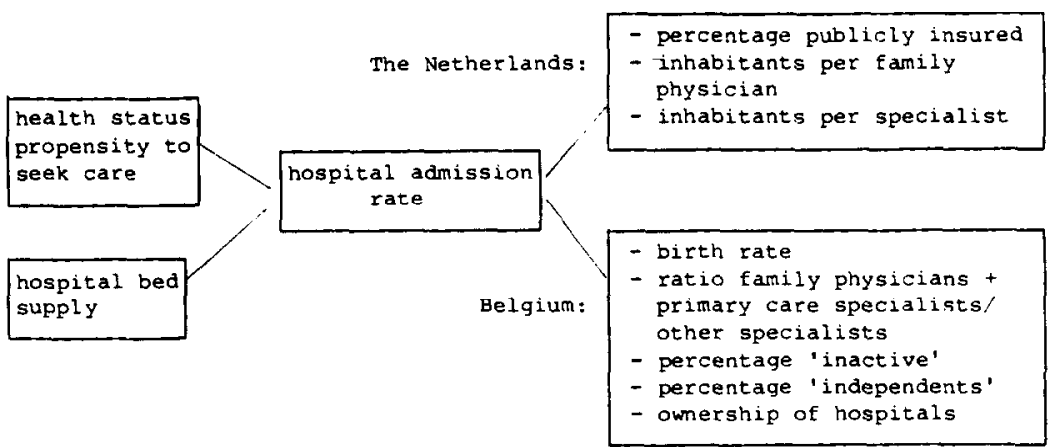

Fig. 2. Schematic representation of the general and specific model to explain regional variation in hospital admission rates.

deliveries either take place at the patients home or involve only a very short hospital stay, which is not counted as an admission [13]. In Belgium on the other hand nearly all deliveries involve a hospital admission. Regional differences in birth rate may, therefore, have a greater influence on hospital admission rates in Belgium than in the Netherlands. In Fig. 2 we have summarized the relations in the general and specific model.

\section{RESULTS}

The data and their sources are more fully described and mapped elsewhere [14]. Our data concern the year 1974, but in our conclusions we will refer also to a reanalysis with 1979 data [15]. We restrict ourselves here to the mean and standard deviation of the variables (Table 1) and a few maps.

The dependent variable-the hospital admission rate, is defined as the number of hospital admissions per 1000 population. This is higher in Belgium than in the Netherlands, but the frequency distributions at least partly overlap (Fig. 3).

Ideally we should begin with a regression analysis on all regions in both countries taken together with the variables of the general model as independents. The results would, however, be uninterpretable, because the level of some of the variables is completely different for the two countries, and therefore the combined distribution is meaningless. The standardized mortality ratio, shown on Fig. 4, is an example. An example of a better distribution of a variable is the number of hospital beds per 1000 population (Fig. 5). Inspection of the scatter plots indicated that there was no reason to model nonlinear relations between the independent variables and the hospital admission rate. Because of the high level of aggregation in this study, problems of multicollinearity can be expected. However all intercorrelations of the independent variables used in the regression equations are less than 0.60 . For the variables indicating the supply of physicians we have for this reason estimated separate equations (see Table 3).

The regression equations have been estimated using the GLIM (Generalized Linear Interactive Modelling) program with regional population size as a weighting variable to account for the differences in size of the regions [16]. The scatter plot of population size and unweighted regression residuals shows a decreasing variation of the residuals with increasing population size.

Table 2 gives the results of the regression of the variables of the general model on the number

Table 1. Mean and standard deviation of the variables used

\begin{tabular}{|c|c|c|c|c|}
\hline \multirow[b]{2}{*}{ Variable } & \multicolumn{2}{|c|}{ Belgium } & \multicolumn{2}{|c|}{ The Netherlands } \\
\hline & Mean & SD & Mean & SD \\
\hline \multicolumn{5}{|l|}{ Dependent variable } \\
\hline Hospital admission rate & 117.6 & 14.47 & 104.0 & 11.40 \\
\hline \multicolumn{5}{|l|}{ General model } \\
\hline Percentage $65+$ & 13.97 & 2.20 & 10.43 & 2.18 \\
\hline Standardized mortality rate & 10.84 & 0.93 & 8.98 & 0.51 \\
\hline Mean income (z-scores) & 0.00 & 1.00 & 0.00 & 1.00 \\
\hline Population density & 470.00 & 978.4 & 724.00 & 872.9 \\
\hline Hospital beds per 1000 & 4.80 & 0.94 & 4.58 & 0.15 \\
\hline Average length of stay & 13.95 & 2.11 & 15.20 & 1.70 \\
\hline \multicolumn{5}{|l|}{ Specific model } \\
\hline Birth rate & 13.51 & 0.93 & 13.54 & 1.86 \\
\hline Ratio family physicians + primary care specialists/other specialists & 2.79 & 0.59 & 2.94 & 1.30 \\
\hline Inhabitants per family physician & 1686.0 & 315.46 & 2979.9 & 269.12 \\
\hline Inhabitants per specialist & 1766.1 & 495.20 & 2906.0 & 1286.26 \\
\hline Percentage publicly insured & - & - & 68.0 & 5.26 \\
\hline Percentage 'non-actives' & 23.2 & 4.05 & - & - \\
\hline Percentage 'special scheme' & 20.8 & 7.22 & - & - \\
\hline Percentage hospital beds owned by health insurance funds & 13.0 & 22.91 & - & - \\
\hline
\end{tabular}




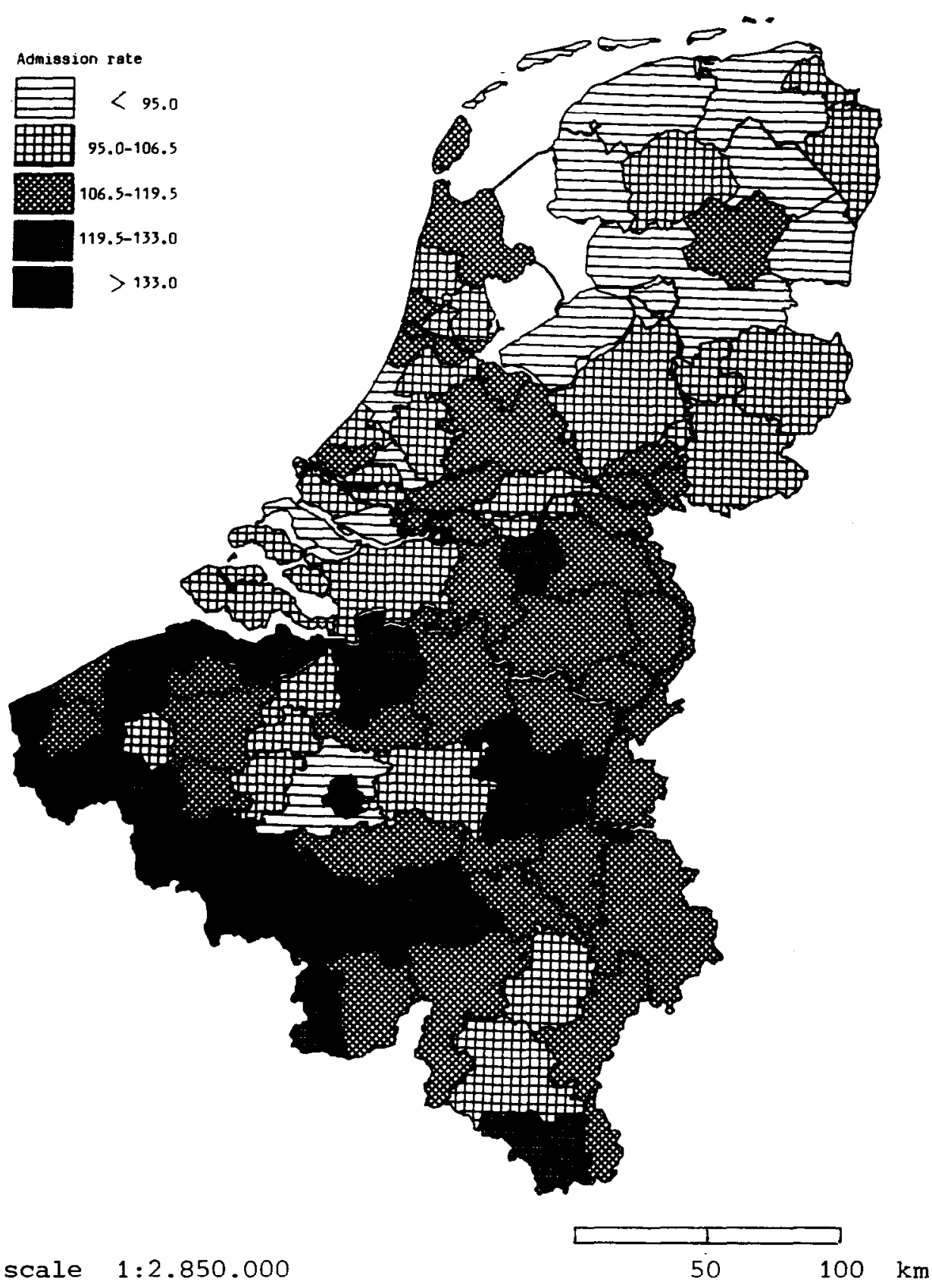

Fig. 3. Geographical distribution of hospital admission rates in Belgium and the Netherlands (1974).

of hospital admissions for the Netherlands and Belgium. Among the indicators on the demand side. only the mortality rate shows the expected significant coefficient for both countries. Income-as an indicator of the socio-economic situation in a regionand population density, have a significant coefficient only in Belgium. In the 1979 data we found a positive and significant coefficient for the standardized mortality rate in Belgium. The supply side hypothesis that an increased number of hospital beds coincides with a higher admission rate, remaining constant for average length of stay, is not rejected. The relation is stronger in the Netherlands (where the average length of stay has an independent influence on admission rate).

These results show the way for the rest of the analysis. For both countries we compute the residual admission rates that remain after the influence of the mortality rate and the number of hospital beds has been eliminated. The estimated number of hospital admissions is computed as:

Belgium:

$$
\begin{aligned}
\text { Admissions } & =38.70+(4.100 \times \text { beds }) \\
& +(5.400 \times \text { mortality }) \quad\left(r^{2}=0.25\right)
\end{aligned}
$$




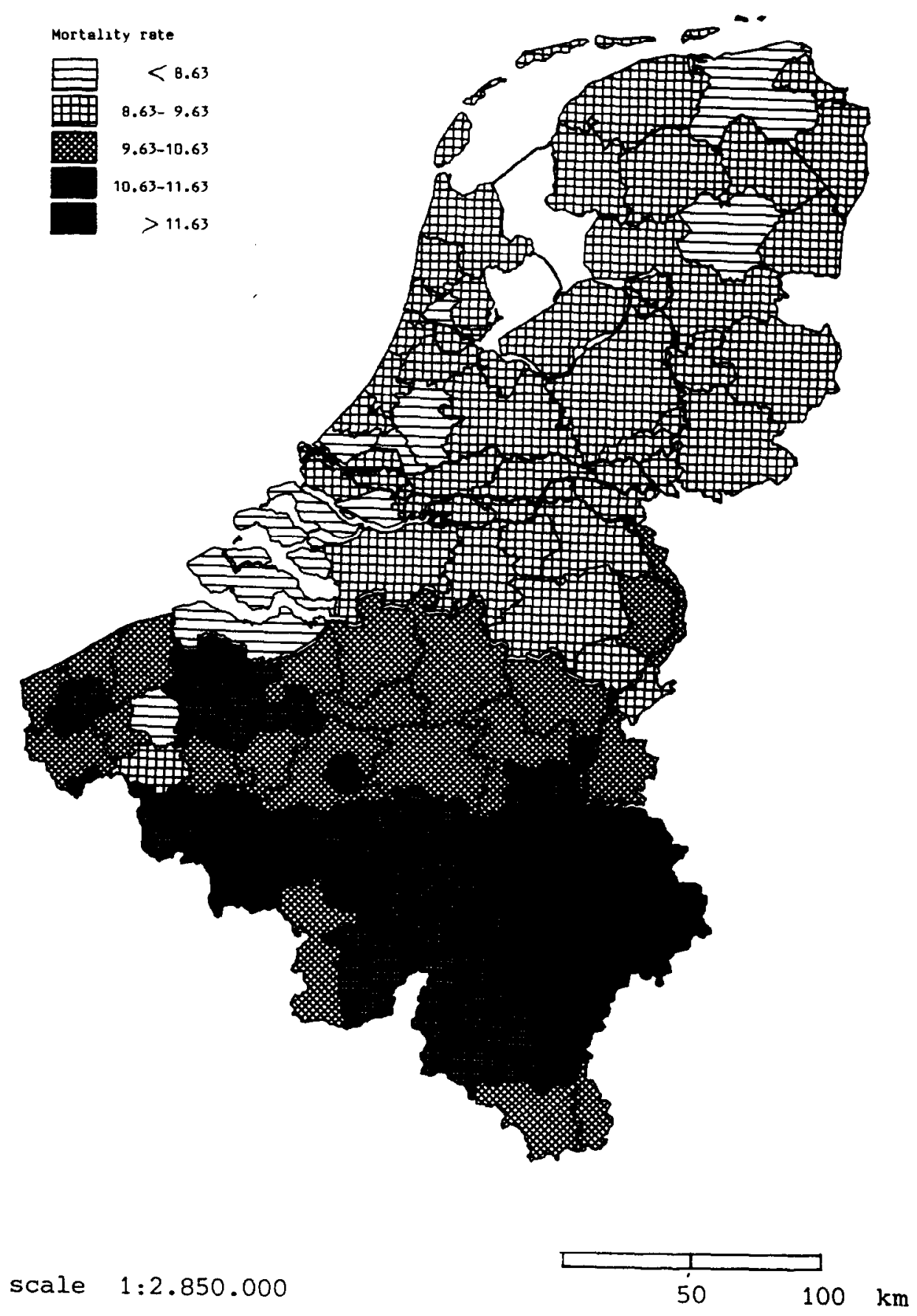

Fig. 4. Age adjusted death rates for 85 districts in Belgium and the Netherlands (1974).

The Netherlands:

$$
\begin{aligned}
\text { Admissions } & =7.58+(8.468 \times \text { beds }) \\
& +(6.295 \times \text { mortality }) \quad\left(r^{2}=0.41\right) .
\end{aligned}
$$

In the next stage of the analysis, we attempt to explain the variation in actual admission rates and the admission rates adjusted for the two variables that had a significant influence in the general model. We use the variables of the specific model as indepen- dent variables. These can be divided into variables for which we expect different relations with the residual admission rate in Belgium and the Netherlands, and those which only exist in one of the health care systems (the insurance variables and the ownership of hospitals in Belgium and the percentage of publicly insured patients in the The Netherlands).

The regression analysis for the variables that 'exist' in both health care systems, but for which a differential effect on the residual admission rate is 


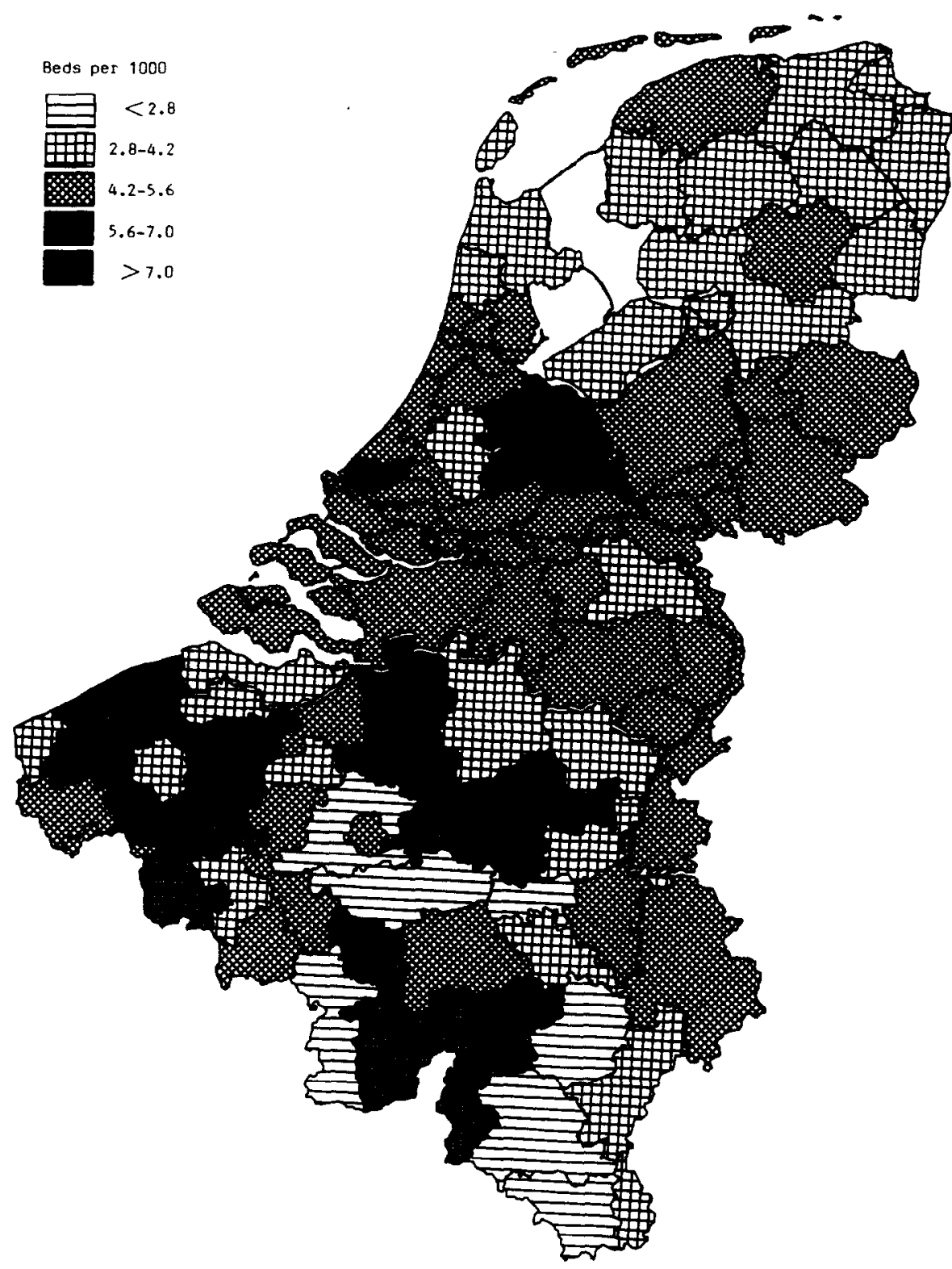

scale $1: 2.850 .000$

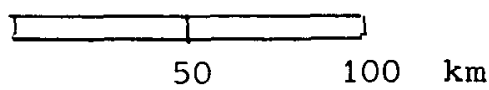

Fig. 5. The number of acute medical and surgical hospital beds per 1000 inhabitants for 85 districts in Belgium and the Netherlands (1974).

expected, is given in Table 3. Different equations have been estimated for the different indicators of the supply of physicians, because of the high intercorrelations. In regions in Belgium with a higher birth rate, there is also a higher hospital admission rate than expected on the basis of bed supply and mortality. However, in the 1979 data this relationship was not found. In the Netherlands there is no such relationship.
The associations between the physician-supply variables and residual admission rates are promising for the Belgian case: in regions with a relatively high number of family physicians and primary care specialists, compared with the number of other, mostly hospital based specialists, the hospital admission rate is relatively low. The opposite, although not statistically significant, exists in the Netherlands. This was unexpected. The associations that were predicted 
Table 2. Regression of the variables of the general model on the number of hospital admissions in Belgium and the Netherlands*

\begin{tabular}{|c|c|c|c|c|}
\hline & \multicolumn{2}{|c|}{ Belgium } & \multicolumn{2}{|c|}{ The Netherlands } \\
\hline & B & $T$ & B & $\mathrm{T}$ \\
\hline Percentage $65+$ & -0.85 & -0.76 & 0.15 & 0.18 \\
\hline Standardized mortality tate & 5.46 & 1.92 & 5.79 & 1.98 \\
\hline Mean income & -4.69 & $-\overline{2.08}$ & -0.81 & $-\overline{0.58}$ \\
\hline Population density $\times 10^{-2}$ & 0.40 & 2.67 & -0.01 & -0.10 \\
\hline Hospital beds per 1000 & 4.23 & 3.56 & 12.47 & $\underline{4.58}$ \\
\hline Average length of stay & -1.38 & -0.94 & -2.21 & -1.81 \\
\hline Constant & 66.87 & 1.82 & 26.22 & 0.91 \\
\hline$\widetilde{R}^{2}$ & \multicolumn{2}{|c|}{0.32} & \multicolumn{2}{|c|}{0.44} \\
\hline$N$ & \multicolumn{2}{|c|}{43} & \multicolumn{2}{|c|}{42} \\
\hline
\end{tabular}

Table 3. Regressions of the variables for which a different effect for each country is expected, on the difference between the actual and estimated number of hospital admissions ( $B$-coefficient and $t$-statistics)

\begin{tabular}{|c|c|c|c|c|c|c|}
\hline & $\mathrm{B}^{*}$ & $\mathbf{N}$ & $\mathbf{B}$ & $\mathbf{N}$ & $\mathbf{B}$ & $\mathbf{N}$ \\
\hline Birth rate & $\frac{6.17}{(3.67)}$ & $\begin{array}{c}0.15 \\
(0.23)\end{array}$ & $\frac{3.91}{(1.89)}$ & $\begin{array}{c}0.32 \\
(0.54)\end{array}$ & $\frac{6.67}{(3.32)}$ & $\begin{array}{l}-0.01 \\
(-0.02)\end{array}$ \\
\hline $\begin{array}{l}\text { Ratio family physician + primary care } \\
\text { physician/other specialists }\end{array}$ & $\frac{-16.27}{(-4.11)}$ & $\begin{array}{c}1.62 \\
(0.96)\end{array}$ & - & - & - & - \\
\hline Inhabitants per family physician $\times 10^{2}$ & - & - & $\begin{array}{l}-0.0074 \\
(-0.01)\end{array}$ & $\begin{array}{c}0.36 \\
(0.80)\end{array}$ & - & - \\
\hline Inhabitants per specialist $\times 10^{2}$ & - & 一 & - & - & $\frac{-1.01}{(-2.74)}$ & $\begin{array}{r}0.15 \\
(1.19)\end{array}$ \\
\hline Constant & $-\frac{50.07}{(-2.37)}$ & $\begin{array}{c}-4.90 \\
(-0.64)\end{array}$ & $\frac{-51.71}{(-2.05)}$ & $\begin{array}{l}-15.30 \\
(-1.14)\end{array}$ & $\frac{-72.79}{(-2.99)}$ & $\begin{array}{c}-3.57 \\
(-0.46)\end{array}$ \\
\hline$R^{2}$ & 0.34 & 0.03 & 0.08 & 0.01 & 0.22 & 0.03 \\
\hline
\end{tabular}

* $\mathbf{B}=$ Belgium; $\mathbf{N}=$ The Netherlands.

for the Netherlands are not found (although the sign of the coefficients for each of the physician supply indicators is the opposite of those in the Belgian case). These results indicate that there may indeed be something wrong with incentives in the Dutch health care system.

We now observe the influence of the insurance related variables and the ownership of Belgian hospitals. In the Netherlands there is a weak positive correlation between the percentage of publicly insured patients and the residual admission rate $(r=0.19)$; the relation is somewhat stronger in $1979(r=0.33)$, but diminishes when other variables are introduced. The regression results are given in Table 4.

In this equation we have also introduced the variables which showed significant associations in the earlier equations (birth rate and ratio of family physicians + primary care specialists and other specialists). The variables representing unique features of the Belgian health care system do not show an independent influence on the residual admission rate. In an ordinary least squares analysis of the data [17], the proportion of 'non-actives' - the group for which co-payment is nil-was clearly related to the residual admission rate. This difference between the OLSanalysis and the analysis with population size as a weighting variable could be attributed to the fact that in the last analysis standardized mortality has a significant coefficient in both countries. In the OLS version standardized mortality was not significant and consequently not used in the computation of the residuals. To the extent that the proportion of nonactives (old age pensioners, widowers and handicapped people) is also an indicator of health status, these results would be interpretable. In the 1979 data

Table 4. Regression of the variables representing unique features of the Belgian and Dutch health care system, on the difference between actual and estimated number of hospital admissions

\begin{tabular}{lrr}
\hline & B & T \\
\hline Belgium & & \\
Percentage 'non-actives' & 0.47 & 1.02 \\
Percentage 'special scheme' & 0.35 & 0.75 \\
Percentage of hospital beds owned by health insurance funds & 0.017 & 0.17 \\
Birth rate & $\frac{5.75}{7.46}$ & -2.08 \\
Ratio of family physicians and primary care physicians/other specialists & $\frac{-17}{58.55}$ & -2.58 \\
Constant & \multicolumn{2}{c}{0.33} \\
$R^{2}$ & & \\
The Netherlands & 0.34 & 0.15 \\
Percentage publicly insured & -1.258 & -1.99 \\
Average length of stay & 17.41 & 0.96 \\
Constant & \multicolumn{2}{c}{0.07} \\
$R^{2}$ & & \\
\hline
\end{tabular}


to which we referred above, mortality has a signifcant coefficient only for Belgium, but in that case the proportion of non-actives was related to the residual admission rate.

\section{DISCUSSION}

The main line of reasoning in this paper is that international comparison of health care systems is always hampered by the small number of units that are analysed. The effort required to gather data on a sufficient number of health care systems-say 50-to allow for statistical analysis is practically prohibitive. In our view there are two possible solutions for this problem. One is to enlarge the number of observations by using time series data for a small number of health care systems. The other is to use regional data for a small number of systems.

The problem with the first solution is that it is very difficult to find time series data over a sufficient length of time-even for one health care system. We have therefore chosen the second option. Our analysis must be regarded as a preliminary exercise that shows promising prospects.

As our central theme we have chosen to observe variations in the number of hospital admissions. The reason for that is a practical one: data on hospital admissions are available in most health care systems, at least in Belgium and the Netherlands. The strategy for the analysis is as follows: there are a number of influences on regional variations in admission rates which are independent of the specific health care system under study. These are general in the limited sense that their influence will be the same in western industrialized countries. In addition to this, there are variables which either have a different influence in each system or are merely present in one or the other system.

To predict the influence of these specific variables an analysis has been made of the incentive structure governing the behaviour of relevant groups of actors: family physicians, medical specialists and hospitals and of the insurance systems. The conclusion of our analysis must be that the distinction between general and system specific components of a model for the explanation of regional variation in hospital admissions is only partially successful. Precise predictions are hard to obtain as yet because of the high level of aggregation and the derivitive position of hospital admissions in a health care model, so that the interpretations of 'confirmed' and refuted expectations are a bit arbitrary. The limited success (in terms of explained variance) of the 'general model' transfer the main emphasis in the analysis to the separate countries. The number of districts per country (approx. 40), however, is rather small for a multivariate analysis. The original number of 85 regions suited this purpose better.

Again, it is difficult to interpret the effects of system-related variables on hospital admissions. If these predictions are unclear, the analysis begins to look like an 'ordinary' contextual analysis with only two contexts and again the issue of the number of observations rears its head. Our view is that the only analysis that makes sense is one that examines the effective mechanisms found at the regional level, taking into account the incentive structure of the health care systems involved.

Acknowledgement -We gratefully acknowledge the help of our colleague Jan Kerssens in the GLIM computations

\section{REFERENCES}

1. An example of a study using regional analysis of different health care systems in McPherson K., Strong P. M., Epstein A. and Jones L. Regional variations in the use of common surgical procedures: within and between England and Wales. Canada and the United States of America. Soc. Sci. Med. 15A, 273-288, 1981.

2. Raffel M. W. (Ed.) Comparative Health Systems; Descriptive Analysis of Fourteen National Health Systems. Pennsylvania State University Press, 1984.

3. Blanpain J., Delesie L. and Nys H. National Health Insurance and Health Resources. Harvard University Press, Cambridge, Mass., 1978.

4. Glaser W. A. Health Insurance Bargaining: Foreign Lessons for Americans. Gardner Press, New York, 1978.

5. Roemer M. I. and Roemer R. J. Health Care Systems and Comparative Manpower Policies. Marcel Dekker, New York, 1981.

6. It is however not impossible as is shown in quantitative, comparative research in political science and cultural anthropology.

7. 7. Rothberg D. L. Regional variations in hospital use: introduction and overview. In Regional Variations in Hospital Use (Edited by Rothberg D. L.). Lexington Books, Lexington, Mass., 1982.

8. This may be an important variable, because of the great difference in the number of beds in nursing homes between the Netherlands and Belgium. Compare: Groenewegen P. P. and Leroy X. Aanbodzijde in de Belgische en Nederlandse gezondheidszorg. In Basisgegevens van de Belgische en Nederlandse Systemen van Gezondheidszorg en Sociale Zekerheid bij Ziekte en Invaliditeit (Edited by Peeters R. F., Stevens F. C. J. and Van der Zee J.). Van Loghum Slaterus, Deventer, 1985.

9. The tendency to refer patients is restriced by the rising attention to peer review and review procedures by health insurance funds and private insurance companies.

10. Van Tits M. H. L., Nuyens W. J. F. I. and Hoeksma B. H. Substitutie Kliniek polikliniek. IVG, Tilburg. 1981.

11. Voluntary public insurance will be abolished in 1986

12. Van der Ven W. P. M. M. and Van Vliet R. C. J. A Effects of cost-sharing in the health care sector. Gezondh. Samenlevg 6, 238-244, 1986. Mootz M. The need for health care utilization and its relation to insurance coverage for medical expenses. Gezondh. Samenlevg 6, 232-237, 1986.

13. Hingstman L. and Boon $H$. Geographical aspects of obstetrical care in the Netherlands. Paper of the $A A G-I B G$ Conference, Rutgers University, New Brunswick, 14-18, July 1986.

14. Groenewegen P. P. and Van der Zee J. Hospital Admissions in the Dutch and Belgian Health Care Systems; an Analysis of Regional Variation. Netherlands Institute of Primary Health Care, Utrecht, 1985.

15. Appendix to the report cited in Ref. [14]

16. Baker R. J. and Nelder J. A. The GLIM System; release 3. Numerical Algorithms Group, Oxford, 1978.

17. The estimations in the original report (Ref. [14]) were all ordinary least squares (OLS) estimations. 